\title{
Variação temporal da descarga sólida em suspensão e identificação de minerais a partir de aperfeiçoamento de método de amostragem automática no Córrego Riacho Fundo, Brasília, Distrito Federal \\ Temporal variation of suspended sediments and mineralogy using an improved automatic sampler system in the Riacho Fundo Stream, Brasilia, Distrito Federal, Brazil

\author{
Igor Guedes de Aquino", Henrique Llacer Roig', Elton Souza Oliveira, \\ Jérémie Garnier ${ }^{1}$, Edi Mendes Guimarães ${ }^{1}$, Sérgio Koide ${ }^{2}$ \\ ${ }^{1}$ Instituto de Geociências, Universidade de Brasília - UnB, Campus Universitário Darcy Ribeiro, Asa Norte 70910900, Brasília, \\ DF, BR (igorambientais@gmail.com; roig@unb.br; elton.gea@gmail.com; garnier@unb.br; rxedi@unb.br) \\ 2Departamento de Engenharia Civil e Ambiental, Universidade de Brasília - UnB, Brasília, DF, BR (skoide@unb.br)
}

Recebido em 09 de novembro de 2017; aceito em 21 de maio de 2018

\begin{abstract}
Resumo
Este estudo buscou contribuir com informações sedimentométricas sobre o Córrego Riacho Fundo (CRF), afluente do Lago Paranoá, Brasília, Distrito Federal, historicamente o principal transportador de sedimentos da bacia. Utilizamos método acústico com o equipamento River Surveyour M9 da Sontek, para levantamento de vazão, e amostrador automático ISCO 6712, para amostragem de água e sedimentos, com coleta em ponto fixo em relação ao leito do córrego e coleta com adaptação para amostragem a $40 \mathrm{~cm}$ de profundidade da superfície d'água. A mineralogia de uma seleção de amostras de sedimentos coletados foi determinada por difratometria de raios X. Além disso, a turbidez das águas foi medida por meio de sonda multiparamétrica flutuando a $40 \mathrm{~cm}$ da superfície. Os resultados obtidos permitiram elaborar uma nova curva-chave do CRF, com vazões medidas em cotas nunca registradas. O novo método de coleta implantado possibilitou obter informações em cotas que não haviam sido amostradas antes e permitiu também diminuir a dispersão dos dados entre concentração e cota. Assim, comparando os dois métodos, com o método fixo obteve-se $\mathrm{R}^{2}=0,28$, e com o método com flutuabilidade, $\mathrm{R}^{2}=0,45$. A adaptação com flutuação também favoreceu uma boa correlação entre turbidez e concentração, apresentando $\mathrm{R}^{2}=0,92$. A análise de histerese mostrou que a maioria dos eventos ocorre no sentido anti-horário. A quantidade total de sedimentos suspensos por evento de chuva variou entre 43 e 1.258 t com o método adaptado, e entre 47 e 10.142 t com o método de coleta fixa. A mineralogia dos sedimentos é composta por saponita, vermiculita, ilita, muscovita, caolinita, gibbsita, diásporo, quartzo, rutilo e hematita. O uso do amostrador automático permitiu identificar maior número de minerais quando comparados outros estudos na região.
\end{abstract}

Palavras-chave: Sedimentometria; Amostrador automático; Turbidez; Mineralogia.

\begin{abstract}
This work aimed to contribute in the sedimentometric study of the Riacho Fundo stream, affluent of Lake Paranoá, Brasília, Federal District, and historically the main sediments exporter for the entire basin. For this purpose, the flow was measured by the acoustic method with the Sontek River Surveyour M9 equipment and an automatic sampler ISCO 6712 was used for water and sediment sampling, with collection at a fixed point and varying according to the height, in a water depth of $40 \mathrm{~cm}$. The mineralogy of chosen sediment samples was assessed by X-ray diffraction. Also, simultaneous monitoring of the turbidity was carried out, with a floating multiparameter probe, likewise. The results are useful data for the location, since there is lack of data for reservoir sedimentation planning. Furthermore, the improved sampling method (floating probe) showed a better coefficient of determination $\left(\mathrm{R}^{2}=0,45\right)$ than the fixed sampling method $\left(\mathrm{R}^{2}=0,28\right)$. Thus, a good correlation could be reached between turbidity and concentration $\left(\mathrm{R}^{2}=0.92\right)$. Hysteresis was generally counterclockwise. The use of the automatic sampler allowed the identification of minerals in the suspended sediments, which are not identified in other studies in the region.
\end{abstract}

Keywords: Sedimentometry; Automatic sampler; Turbidity; Mineralogy. 


\section{INTRODUÇÃO}

Nos últimos anos, a Companhia de Saneamento Ambiental do Distrito Federal (CAESB), entidade responsável pelo abastecimento do Distrito Federal, vem trabalhando na identificação e operacionalização de novas fontes de abastecimento (CAESB, 2017). Entre essas fontes estão: o reservatório de Corumbá IV, que exige uma longa rede de aquedutos, e o Lago Paranoá (LP), localizado no coração da cidade de Brasília.

Nesse contexto, várias pesquisas têm sido realizadas com o objetivo de verificar as condições geoquímicas das águas (Costa, 2014) e dos sedimentos (Moreira e Boaventura, 2003; Costa, 2014; Dias, 2017), as fontes desses sedimentos (Franz et al., 2014) e a evolução do padrão de uso e ocupação da bacia de contribuição (Menezes et al., 2010). Esses estudos têm demonstrado que a Bacia do Lago Paranoá teve, e continua tendo, forte retirada da cobertura vegetal em detrimento da expansão urbana, causando aumento dos processos erosivos e do assoreamento do lago (Menezes, 2010; Menezes et al., 2010; Roig et al., 2013; Hussain et al., 2015). Apesar desses estudos, a quantificação do aporte dos sedimentos provenientes das sub-bacias que aportam o LP e sua distribuição espaçotemporal ainda é incipiente.

Dentre os principais afluentes do LP, um deles se destaca historicamente por ter a maior contribuição para o processo de assoreamento do lago, o Córrego Riacho Fundo (CRF) (Miguel et al., 2017) (Figura 1).

A CAESB tem monitorado os sedimentos suspensos desse córrego com frequência mensal desde novembro de 2011, seguindo os protocolos estabelecidos pela Agência Nacional de Águas (ANA, 2012), especificamente o método Igual Incremento de Largura - IIL. Essa estratégia não permitiu a quantificação do transporte de sedimentos de modo apropriado devido à falta de amostragem dos eventos extremos de chuva, os quais são responsáveis pela maior carga de sedimentos suspensos (Carvalho e Massera Da Hora, 2013).

Buscando resolver esses problemas, Aguiar (2015) sugeriu outros métodos que permitissem suprir a demanda da amostragem. O autor observou que o tempo de medição necessário pelo método usado pela CAESB não permite monitorar o evento, pois a resposta às chuvas intensas ocorre em questão de poucas horas, com taxa de elevação do nível do rio de até $1 \mathrm{~m}$ em 30 minutos. Portanto, o autor propôs o uso de
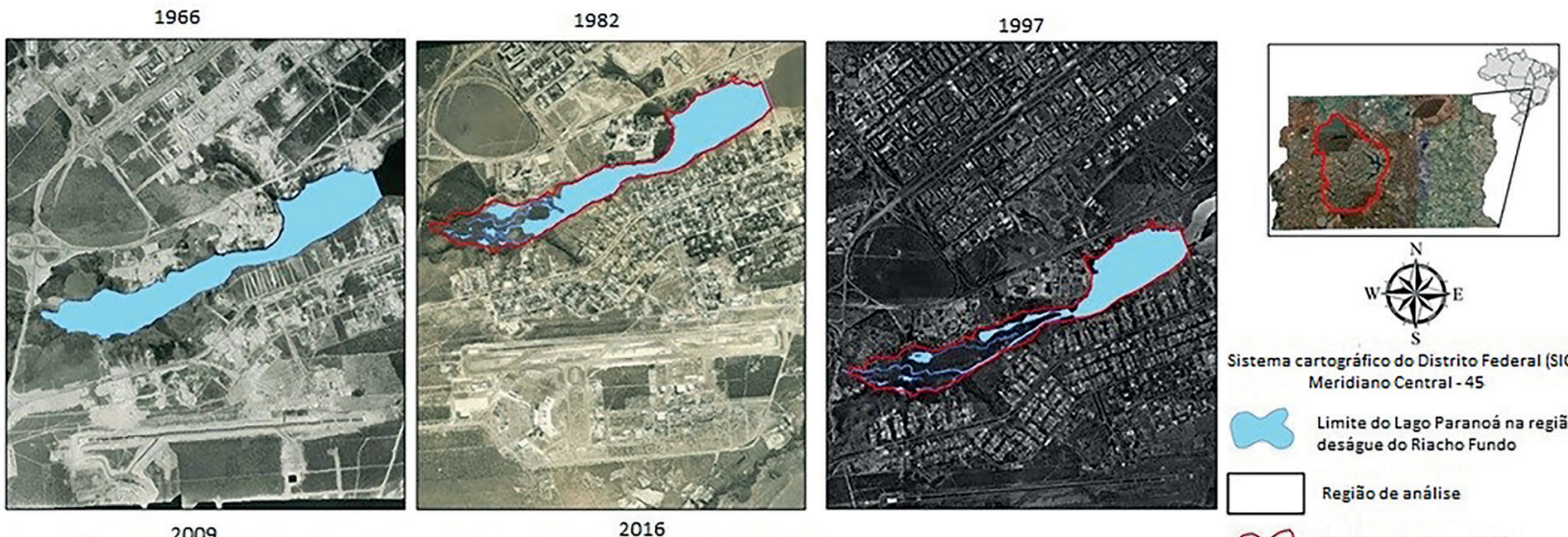

2016
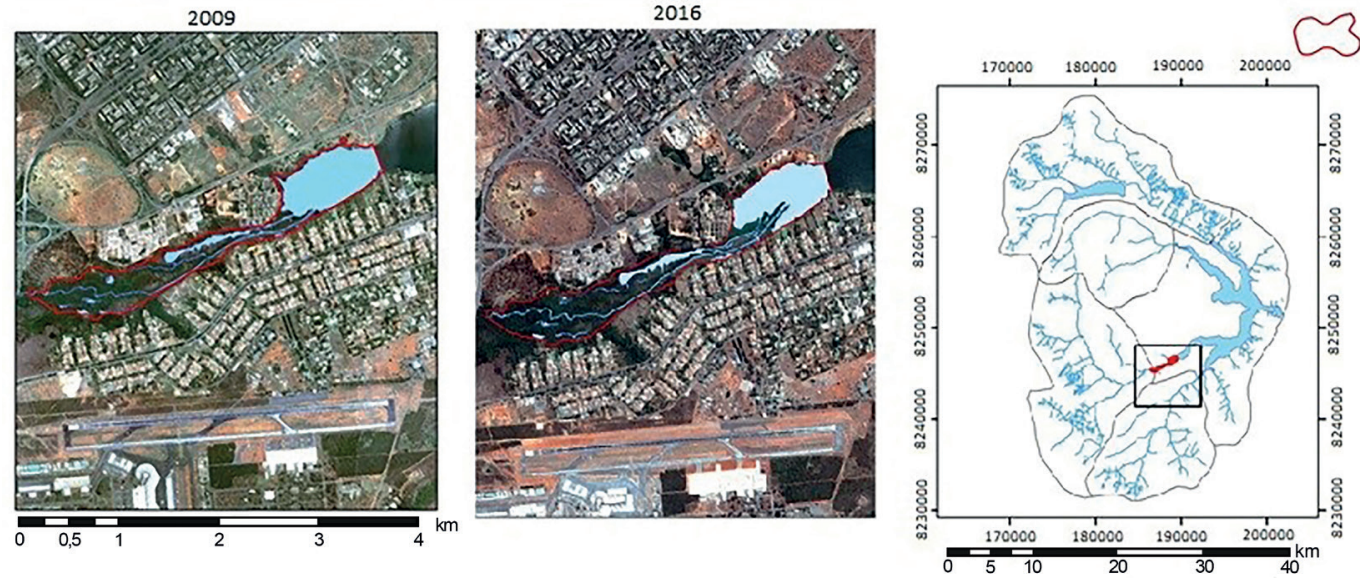

Fonte: complementado e adaptado de Menezes (2010).

Figura 1. Variabilidade do espelho d'água do braço do Riacho Fundo do Lago Paranoá entre 1966 e 2016. 
amostrador automático (ISCO 3700). Embora esse método tenha monitorado os eventos extremos, o que nunca havia sido realizado para a região, o fato de a amostragem ser realizada em um ponto fixo em relação ao leito do rio dificultou a interpretação dos dados, visto que a relação entre a amostragem pontual e a descarga toda do evento não pôde ser correlacionada. Em consequência, durante a subida do nível do rio, as amostras passam a ser mais representativas da carga do leito, e não da carga suspensa. A partir dessas conclusões, este trabalho propôs medir a variação temporal da descarga sólida e identificar minerais com modificações no método usado por Aguiar (2015), com vistas a melhorar a representatividade dos dados, necessários para o entendimento da dinâmica hidrossedimentométrica e, consequentemente, do processo de planejamento de disponibilidade hídrica do LP.

\section{DESCRIÇÃO DA ÁREA DE ESTUDO}

A sub-bacia do RF, com área de $171,26 \mathrm{~km}^{2}$, quanto ao uso e à ocupação, é dividida em uma parte com características predominantemente rurais e uma parte urbana, que apresenta uma alta taxa de urbanização, marcada por incremento significativo a partir de meados da década de 1990 (Menezes, 2010). A bacia pode ser dividida em função de seus dois principais córregos, o homônimo à bacia e o Córrego Vicente Pires (CVP). Este último é o mais urbanizado, enquanto a parte que drena para o CRF é predominantemente rural, com expansão urbana ocorrendo nas suas cabeceiras, representada por condomínios residenciais de baixa renda (Figura 2).

\section{Caracterização geológica e pedológica}

Do ponto de vista geológico, de acordo com Maia et al. (2006), o CRF nasce na Formação Ribeirão Contagem (Unidade Quartzito Médio) e corta as unidades Formação Serra da Meia-Noite (Metarritmito Arenoso) e Formação Ribeirão do Torto (ardósia). Essas unidades são pertencentes ao Grupo Paranoá (Campos et al., 2013). Na Formação Ribeirão Contagem o quartzo compõe mais de $95 \%$ do arcabouço, mas também ocorrem turmalina, magnetita e rutilo. A Formação Serra da Meia-Noite contém quartzo,
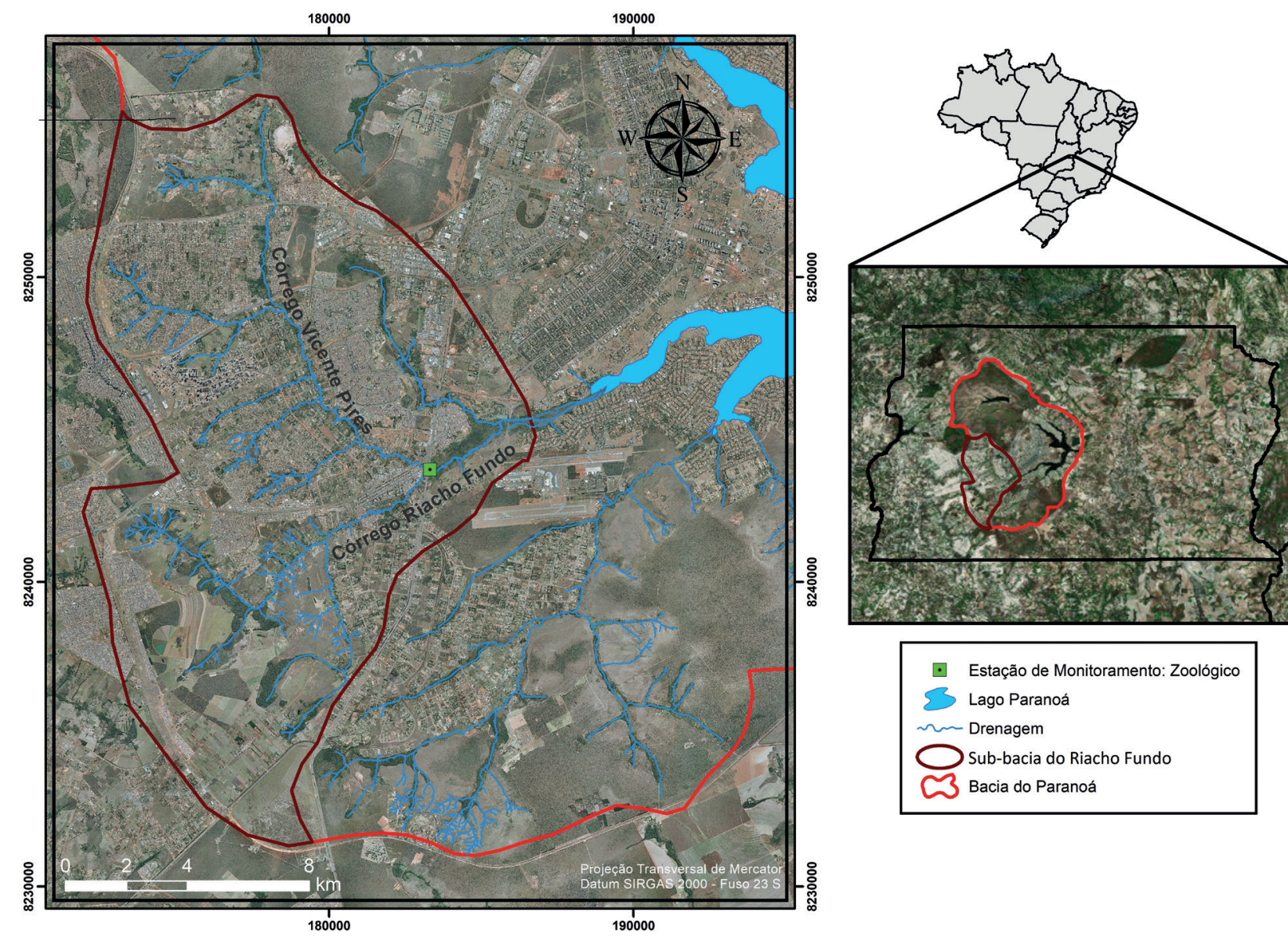

Fonte: bacias - CAESB (2015).

Figura 2. Sub-bacia do Riacho Fundo. O ponto verde corresponde à estação em análise neste trabalho. 
feldspatos $(<10 \%)$, clorita, hematita, caulinita, rutilo e epidoto. Já na Formação Ribeirão do Torto predominam os minerais clorita, fengita, quartzo, hematita e matéria orgânica. Esses minerais citados, das três Formações, representam as rochas frescas e alteradas.

Quanto à pedologia, a região é composta predominantemente por Latossolos, com destaque para o Latossolo Vermelho (38\%), seguido pelo Latossolo Vermelho Amarelo (15\%) e, em menor proporção, por Cambissolo Háplico, Nitossolo Vermelho Plintossolo Pétrico, Gleissolo Háplico, (Reatto et al., 2004; Carvalho, 2013).

Segundo Reatto et al. (1999, 2004), os solos são caracterizados por abundância de minerais secundários do grupo da caulinita, óxidos, hidróxidos e oxi-hidróxidos de ferro e alumínio, como hematita, goethita, gibbsita, entre outros. Mas também ocorrem minerais traço, como vermiculita, rutilo e anatásio.

\section{Caracterização climática}

A sub-bacia do CRF é caracterizada por clima "Tropical de Savana", segundo classificação de Köppen, com estação chuvosa no verão, delimitada pelos meses de outubro e abril (CODEPLAN, 1984). Cerca de $84 \%$ da precipitação total anual ocorrem nesse período (1.200 a $1.700 \mathrm{~mm})$, sendo novembro, dezembro e janeiro os meses mais chuvosos.

\section{MATERIAIS E MÉTODOS}

Neste estudo utilizou-se da estação fluviossedimentométrica Montante Zoológico (Código: 60478200 -1551'52”S e $\left.-47^{\circ} 57^{\prime} 25^{\prime \prime} \mathrm{W}\right)$, gerenciada pela CAESB, para os levantamentos hidrossedimentométricos. Essa estação foi escolhida devido à sua proximidade com o exutório da sub-bacia (Figura 2).

O trabalho foi realizado com as seguintes etapas:

(i) complementação da infraestrutura e reconfiguração do sistema de amostragem automático e da sonda, para acompanhar a variação de nível durante os eventos de cheia;

(ii) análise do histórico dos perfis topobatimétricos da seção transversal da estação em questão e complementação dos dados durante a execução deste trabalho (2016-2017);

(iii) medição de vazão com equipamento acústico;

(iv) coleta das amostras de sedimento em suspensão com o amostrador automático;

(v) construção da curva-chave de vazão;

(vi) processamento das amostras de sedimentos em suspensão em laboratório (concentração, parâmetros físicos e mineralogia);

(vii) análise dos resultados obtidos.

\section{Complementação da infraestrutura}

Além da infraestrutura existente - Plataforma de Coleta de Dados (PCD) com pluviógrafo, medidor de nível e régua o amostrador automático e a sonda multiparamétrica foram instalados/reconfigurados.

\section{Amostrador automático ISCO 6712}

Para amostragem com o ISCO 6712, fixou-se o detector de inicialização do processo na cota $1,4 \mathrm{~m}$ da régua. Desse modo, o equipamento somente inicia o processo de amostragem da mistura água sedimento quando o nível do rio atinge essa cota. Esse sistema opera com intervalo de 15 minutos amostrando todo o evento até que o nível retorne a cota de partida $(1,4 \mathrm{~m})$. Já o filtro coletor do amostrador foi instalado em um tubo de PCV de $50 \mathrm{~mm}$ de diâmetro perfurado com furos de $5 \mathrm{~cm}$ de diâmetro orientados na direção do fluxo e perfazendo aproximadamente $40 \%$ da área do cano. $\mathrm{O}$ coletor foi acoplado a uma boia que permitiu mantê-lo flutuando livremente a uma profundidade de $40 \mathrm{~cm}$ (Figura 3 e Figura 4).

\section{Sonda Hydrolab DS5X (turbidez)}

Devido às características da sonda, ela foi instalada em um sistema similar, porém com cano de $200 \mathrm{~mm}$, de modo a mantê-la flutuando livremente na mesma profundidade do amostrador (Figura 4), o que assegurou a coleta de amostras similares e sob as mesmas condições de vazão e profundidade. O equipamento era mantido em funcionamento por uma bateria com recarga solar, para garantir o monitoramento contínuo da turbidez (medição a cada 15 minutos).

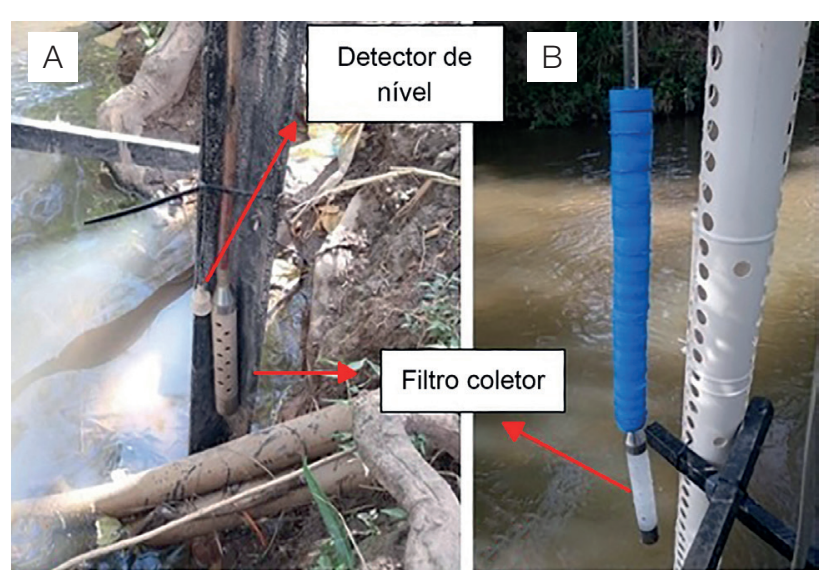

Figura 3. (A) Amostragem fixa de água e sedimentos. (B) Adaptação para flutuabilidade do filtro coletor a $40 \mathrm{~cm}$ de profundidade em relação à superfície da água. 


\section{Levantamento da seção topográfica}

Foi empregada a metodologia de Nivelamento Geométrico por Visadas Extremas (Veiga et al., 2012), a mesma utilizada pela CAESB e pela Agência Reguladora de Águas, Energia e Saneamento Básico do Distrito Federal (ADASA), o que permitiu a comparação do levantamento realizado no projeto com os arquivos da CAESB e da ADASA.

\section{Medição de vazão}

Para determinação de vazão, foi utilizado o método acústico, por meio do equipamento River Surveyor ${ }^{\circledR}$ M9, da Sontek. A metodologia empregada é a mesma estabelecida pela ANA e foram realizados, pelo menos, três perfilagens por cota ou variação de cota. Os tempos de percurso da seção normalmente eram inferiores a um minuto. Todos os dados foram armazenados no aplicativo do próprio equipamento e depois transferidos para a base de dados.

\section{Curva-chave}

Para a geração da curva chave de vazão, empregou-se uma função exponencial (Equação 1), conforme descrito na literatura (Te Chow, 1988; Jaccon, 1989).

$\mathrm{Q}=\mathrm{a}(\mathrm{h}-\mathrm{h} 0)^{\mathrm{n}}$

Em que:

$\mathrm{Q}=$ vazão $\left(\mathrm{m}^{3} / \mathrm{s}\right)$;

$\mathrm{h}=$ cota correspondente à vazão;

$\mathrm{h} 0=$ cota correspondente à vazão nula;

$\mathrm{a}, \mathrm{n}=$ constantes determinadas para o local.

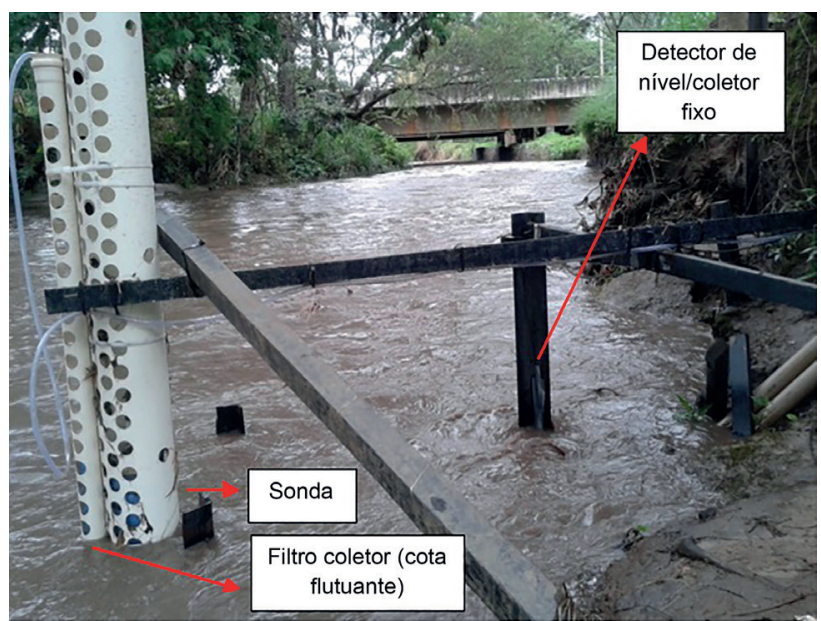

Figura 4. Estrutura para sonda e amostragem de sedimento com variação da cota e lance de réguas em funcionamento.
A curva-chave foi determinada/elaborada no software SIADH 2.0 e utilizando a ferramenta "solver" para a determinação dos parâmetros a, h0 e n.

Calcularam-se o desvio absoluto médio entre os dados obtidos pela curva-chave e a vazão medida em campo. Assim, o conceito de desvio no presente trabalho foi dado pela diferença percentual entre os valores de vazão calculados e medidos. Para tanto, aplicou-se a seguinte expressão (Equação 2):

Desvio $(\%)=\left(\frac{\text { Qcalc }- \text { Qmed }}{\text { Qmed }}\right) \times 100 \%$

Em que:

Qcalc $=$ vazão calculada;

Qmed = vazão medida .

O desvio (\%) é um critério utilizado pela ANA para validação de curva-chave. Inicialmente, era aceito um desvio absoluto médio de até $20 \%$, sendo atualmente considerado um de, no máximo, 10\% (ANA, 2011).

Como parte do processo de análise de consistência de dados verificou-se a dispersão dos desvios em relação à cota e ao tempo. Além disso, foi feita a seleção de dados, de modo a excluir aqueles inconsistentes (gerados por erro na medição de campo, como falha momentânea no cálculo da área molhada ou profundidade, por exemplo).

\section{Processamento das amostras em laboratório}

Para a quantificação da concentração dos sedimentos em suspensão, foram empregados o método de filtração (Carvalho et al., 2000), quando a turbidez de bancada indicava valores inferiores a 200 nephelometric turbidity unit (NTU), e o método evaporação a $90^{\circ} \mathrm{C}$ (ANA, 2012), quando a turbidez alcançava valores iguais ou superiores a 200 NTU. Destaca-se que esse também é o método utilizado pela CAESB e pela ADASA para as estações do DF.

\section{Cálculo da descarga sólida}

A partir dos dados de concentração (mg/L), calculou-se a descarga sólida para cada coleta a partir da Equação 3 (Carvalho et al., 2000):

Qss $=0,0864 . q i . C i$

Em que:

Qss = descarga sólida instantânea (t/dia);

qi = descarga líquida instantânea $\left(\mathrm{m}^{3} / \mathrm{s}\right)$;

$\mathrm{Ci}=$ concentração $(\mathrm{mg} / \mathrm{L})$. 
Após obtenção desses dados, a descarga sólida total de cada evento foi calculada de acordo com a área da curva de descarga gerada pelo sedimentograma, com as devidas correções de unidades. Desse modo, a cada dois dados coletados de concentração, representados no gráfico de descarga sólida instantânea versus tempo, calculou-se a descarga sólida parcial por meio da área de trapézio. Fazendo isso, no intervalo gráfico entre dois dados de concentração (transformada em descarga sólida instantânea pela Equação 3 e somando as descargas sólidas parciais tem-se a descarga sólida total para o evento.

\section{Determinação da composição mineral}

Para análise da composição mineral, foram coletadas amostras de $1 \mathrm{~L}$ da mistura água-sedimento. As amostras foram secas por meio da evaporação em béqueres a $90^{\circ} \mathrm{C}$, em uma chapa aquecedora da marca Quimis, no Laboratório de Geoquímica do Instituto de Geociências (IG) da Universidade de Brasília (UnB). O sedimento foi analisado no difratômetro de raios-X do tipo RIGAKU Ultima IV, no Laboratório de Raios X, do mesmo instituto. $\mathrm{O}$ equipamento é operado com tubo de cobre e filtro de níquel, sob $30 \mathrm{kV}$ e $15 \mathrm{~mA}$.

Com relação à interpretação dos difratogramas, utilizouse como ferramenta auxiliar o software JADE 9.0, da MDI. Para isso, foram adotadas as seguintes etapas:

(i) preparação da lâmina de amostra total (tot) para cada amostra, a partir de pó não orientado, com trituração das amostras em gral de ágata;

(ii) preparação das lâminas com somente a fração argila, seguindo os passos: dispersão em água, centrifugação com 750 rpm por 7 minutos, para separar silte e argila; centrifugação a $3.000 \mathrm{rpm}$ por 30 minutos, para recuperação da sobrenadante fração argila, e orientação em lâmina da fração decantada. Essas lâminas foram então deixadas para secarem ao ar e designadas como normais (n). Leitura no difratograma da lâmina normal de cada amostra;

(iii) solvatação, com etileno-glicol (eg), das lâminas da fração de argila orientada, por 12 horas em dessecador. Leitura no difratograma das lâminas com etileno-glicol;

(iv) solvatação, com glicerol (gl), das lâminas da fração de argila orientada com etileno-glicol, por 12 horas em dessecador. Leitura no difratograma das lâminas com glicerol;

(v) aquecimento das lâminas gl, de cada amostra, em mufla, por 3 horas e 30 minutos, a $490^{\circ} \mathrm{C}$. Leitura, no difratograma, das lâminas aquecidas (aq);

(vi) interpretação, com o auxílio do software JADE 9.0, dos resultados dos difratogramas, comparando as lâminas tot, $\mathrm{n}, \mathrm{eg}, \mathrm{gl}$ e aq, entre elas.

\section{RESULTADOS E DISCUSSÃO}

\section{Caracterização do canal do Córrego Riacho Fundo}

Ao longo de todo o período de monitoramento da seção foram levantados oito perfis, sendo o primeiro realizado em 2007.

Como pode ser observado na Figura 5, o perfil da seção de monitoramento entre 2013 e 2014 é marcado por pequenas variações do fundo, porém as margens mostram-se bastante estáveis. Essas variações do fundo com amplitude inferior a $30 \mathrm{~cm}$ são comuns em leitos móveis, como é o caso da seção em estudo, e não comprometem a determinação da curva-chave. Já em 2016 observou-se significativa variabilidade do perfil da seção, mantendo-se praticamente estável no ano seguinte.

Além da variabilidade da seção, foi observada também uma variação ao longo do trecho do rio, logo a montante da estação. Próximo à estação uma das margens apresentou evolução do processo de erosão instalado (Figura 6), contribuindo para o depósito de sedimentos próximo à margem direita ao longo da seção da estação. Esse processo começou a ser agravado após a queda do gabião, presente na margem oposta.

Verificou-se que, além da existência ou queda do gabião, as modificações no leito do RF podem ser também associadas ao aumento da impermeabilização da bacia, o que leva ao aumento do escoamento superficial e a uma maior vazão no córrego. Esse acréscimo na vazão pode provocar a instabilidade do canal pelo aumento do processo erosivo das margens e do fundo. $\mathrm{O}$ aumento dos processos erosivos foi observado e identificado em seção a montante ao longo da bacia, levando, assim, a um maior volume de sedimentos, que acabam por sedimentar na parte mais a jusante da bacia, ao longo do canal e, principalmente, no LP.

Histórico do perfil transversal Riacho Fundo Montante Zoo

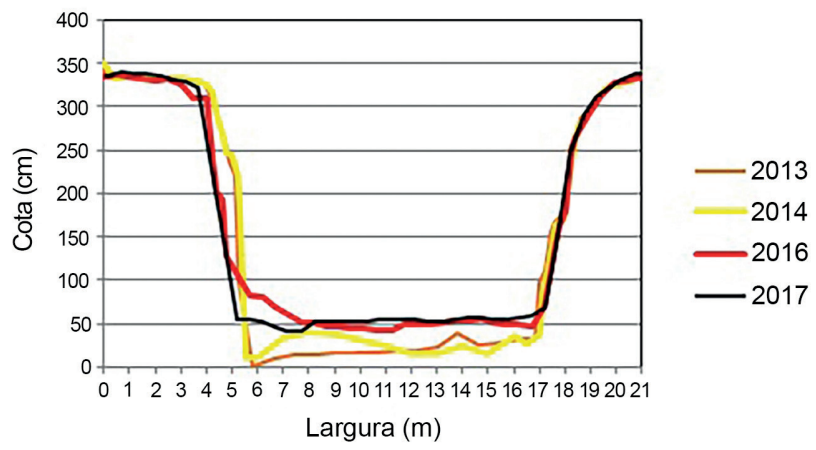

Fonte: dados da CAESB $(2013,2014,2016)$ e do próprio autor (2017).

Figura 5. Histórico do levantamento de perfis transversais (cota versus largura) para a seção da Estação Riacho Fundo Montante Zoológico (60478200 Código ANA). 


\section{Vazão e curva-chave}

Foram realizadas, na estação, 11 campanhas de medições de descarga líquidas (Tabela 1), totalizando 7 horas e 27 minutos ao longo dos anos de 2016 e 2017. Essas campanhas permitiram medir a descarga líquida em uma grande amplitude de cotas, desde as cotas mínimas na época da seca até as enchentes, com variação de cotas de 0,9 até $2,83 \mathrm{~m}$.

A curva-chave resultou na seguinte equação potencial (Equação 4), proveniente da (Equação 1):

$\mathrm{Q}=11,23(\mathrm{~h}-0,59)^{1,52}$

Em que:

$\mathrm{A}=11,23$;

$\mathrm{h} 0=0,59$;

$\mathrm{n}=1,52$;

$\mathrm{Q}=$ vazão $\left(\mathrm{m}^{3} / \mathrm{s}\right)$;

$\mathrm{h}=$ cota correspondente à vazão;

$\mathrm{h} 0=$ cota correspondente à vazão nula;

$\mathrm{a}, \mathrm{n}=$ constantes determinadas para o local.

O desvio absoluto médio da nova curva-chave resultou em $8 \%$, valor aceitável pelos padrões da ANA.

Na comparação da curva-chave da CAESB com a curva-chave do presente estudo (Figura 7), é notória a diferença devido à curva-chave da CAESB se basear em medições até a cota máxima de $1,26 \mathrm{~m}$, enquanto a outra curva-chave obteve medições em cotas expressivamente mais elevadas (até 2,83 m). Essa é a principal diferença entre as duas curvas-chave e o traçado delas começa a divergir acima das cotas não medidas pela CAESB (Figura 7).

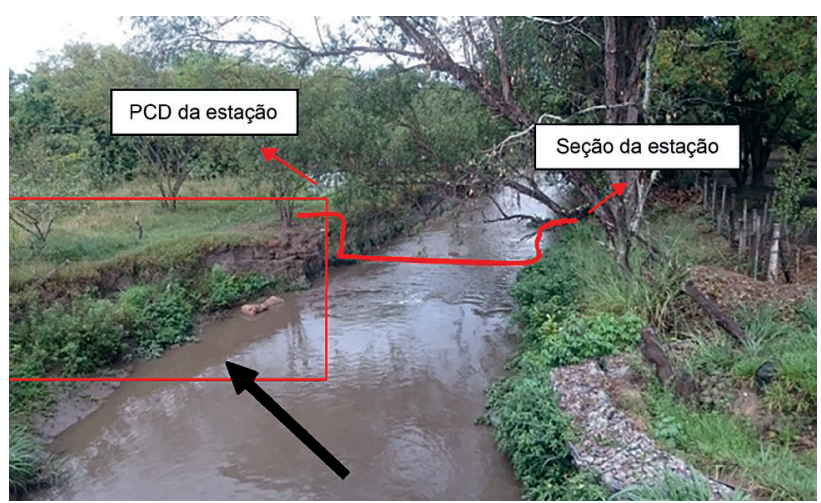

Foto: Elton Souza.

Figura 6. Foto do ano 2017 mostrando erosão na margem esquerda (retângulo vermelho), próxima à Estação Fluviométrica Riacho Fundo Montante Zoológico (Estrada Parque Indústria e Abastecimento 003, Código Agência Nacional de Águas 60478200). Foto tirada de cima de ponte, localizada a montante da estação, na rodovia DF-003 (Estrada Parque Indústria e Abastecimento).
Tabela 1. Vazões medidas pelo M9 e respectivas cotas e datas.

\begin{tabular}{lccccc}
\hline Data & $\begin{array}{c}\text { Cota } \\
(\mathrm{m})\end{array}$ & $\begin{array}{c}\text { Vazão } \\
\text { medida } \\
\left(\mathrm{m}^{3} / \mathrm{s}\right)\end{array}$ & Data & $\begin{array}{c}\text { Cota } \\
(\mathrm{m})\end{array}$ & $\begin{array}{c}\text { Vazão } \\
\text { medida } \\
\left(\mathrm{m}^{3} / \mathrm{s}\right)\end{array}$ \\
\hline $07 / 03 / 2016$ & 2,83 & 37,98 & $17 / 01 / 2017$ & 1,53 & 10,30 \\
$07 / 03 / 2016$ & 2,78 & 37,82 & $17 / 01 / 2017$ & 1,52 & 10,30 \\
$07 / 03 / 2016$ & 2,76 & 34,47 & $18 / 01 / 2017$ & 1,80 & 16,07 \\
$07 / 03 / 2016$ & 2,72 & 34,61 & $18 / 01 / 2017$ & 1,78 & 14,11 \\
$07 / 03 / 2016$ & 2,66 & 36,25 & $18 / 01 / 2017$ & 1,66 & 13,44 \\
$07 / 03 / 2016$ & 2,63 & 34,75 & $18 / 01 / 2017$ & 1,60 & 12,40 \\
$07 / 03 / 2016$ & 2,53 & 32,80 & $18 / 01 / 2017$ & 1,56 & 9,75 \\
$07 / 03 / 2016$ & 2,52 & 31,61 & $18 / 01 / 2017$ & 1,48 & 10,76 \\
$07 / 03 / 2016$ & 2,49 & 31,88 & $18 / 01 / 2017$ & 1,38 & 8,81 \\
$07 / 03 / 2016$ & 2,47 & 30,00 & $18 / 01 / 2017$ & 1,33 & 8,20 \\
$05 / 10 / 2016$ & 0,90 & 1,69 & $18 / 01 / 2017$ & 1,20 & 6,00 \\
$18 / 11 / 2016$ & 0,97 & 1,72 & $18 / 01 / 2017$ & 1,11 & 3,99 \\
$18 / 11 / 2016$ & 0,97 & 2,66 & $03 / 02 / 2017$ & 1,05 & 3,21 \\
$17 / 01 / 2017$ & 2,04 & 18,02 & $06 / 02 / 2017$ & 1,14 & 4,59 \\
$17 / 01 / 2017$ & 1,98 & 15,67 & $07 / 02 / 2017$ & 1,22 & 5,65 \\
$17 / 01 / 2017$ & 1,72 & 11,48 & $08 / 02 / 2017$ & 1,64 & 9,97 \\
$17 / 01 / 2017$ & 1,70 & 13,05 & $26 / 02 / 2017$ & 1,29 & 7,03 \\
$17 / 01 / 2017$ & 1,66 & 12,45 & $27 / 02 / 2017$ & 1,37 & 7,77 \\
$17 / 01 / 2017$ & 1,64 & 11,53 & - & - & - \\
\hline
\end{tabular}

\section{Curva-chave M9 e CAESB}

Curva-chave M9 Curva-chave CAESB

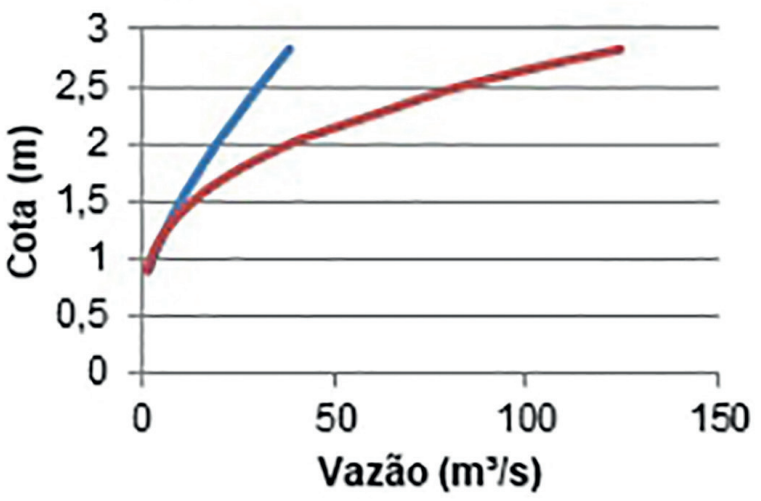

Figura 7. Comparação da curva-chave elaborada pela Companhia de Saneamento Ambiental do Distrito Federal com a curva-chave constituída no presente trabalho. 


\section{Concentração e descarga sólida}

No decorrer do trabalho percebeu-se que muitos eventos de cheia atingiam seu pico em 30 minutos e, assim, a programação do amostrador automático foi alterada para o intervalo de 15 minutos.

Os novos dados, apesar de não refletirem uma correlação entre concentração e vazão suficientemente alta para estabelecer uma curva-chave de sedimentos, permitiram melhorar a correlação. Com uso da amostragem de cota variável, o coeficiente de correlação aumentou de $\mathrm{R}^{2}=0,28$ para $\mathrm{R}^{2}=0,45$.

Durante o trabalho, observou-se que muitos dos eventos de chuva, representados pelo hidrograma de vazão pelo tempo, ocorrem com um padrão, em que dois picos de cheia aparecem no hidrograma (Figura 8). Quando esse padrão ocorre também é possível observar que sempre existe um pico com vazão inferior ao outro pico. Considerando que a bacia pode ser dividida em duas partes, a presença de dois picos de enchente pode ser correlacionada ao funcionamento diferente nessas duas partes da bacia. Sendo assim, o menor pico seria relativo à parte da bacia menos impermeabilizada, anterior à confluência do CRF com o CVP. E o maior pico de vazão poderia ser explicado pelo escoamento superficial decorrente da região mais impermeabilizada da sub-bacia do RF, em que passa somente o segundo córrego (Vicente Pires). Recentemente, pluviógrafos têm sido instalados na sub-bacia, algo que poderá, em trabalhos futuros, auxiliar na compreensão desse fenômeno.

Gao e Josefson (2012), em uma bacia de $311 \mathrm{~km}^{2}$, predominantemente rural, na região central do Estado de Nova York, encontraram concentração máxima instantânea de 4,79

\section{Evento $12 / 03 / 2016$ - 13/03/2016}

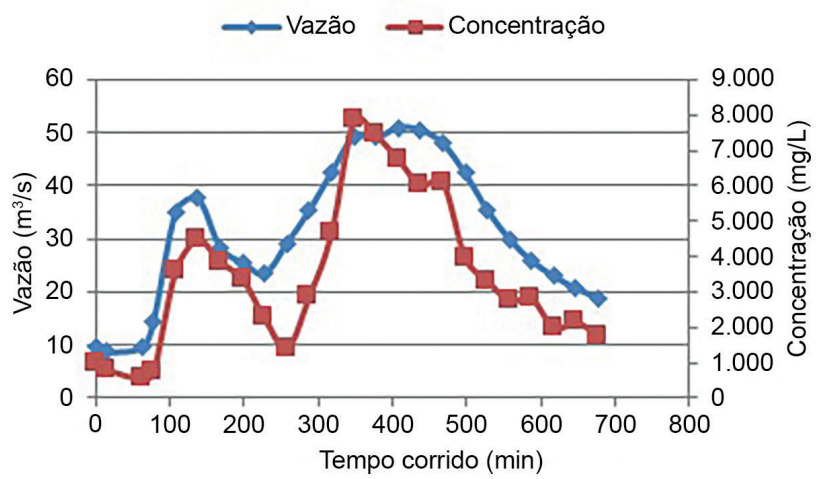

Figura 8. Sedimentograma e hidrograma de evento ocorrido durante período em que a amostragem era feita de forma fixa. No gráfico, cada ponto quadrado representa uma amostra, registrada por linígrafo, no caso do hidrograma, e por amostrador automático ISCO 6712 no sedimentograma. $\mathrm{g} / \mathrm{L}$, na primavera. O pico de vazão máximo durante essa estação foi de $97,71 \mathrm{~m}^{3} / \mathrm{s}$. De Girolamo et al. (2015) registraram concentração máxima de $7,13 \mathrm{~g} / \mathrm{L}$, durante o período chuvoso, associado com uma vazão máxima de $23,50 \mathrm{~m}^{3} / \mathrm{s}$. No entanto, em uma região montanhosa, um evento de chuva no verão com valor de precipitação muito superior à média mensal de precipitação atingiu concentração máxima de $37,6 \mathrm{~g} / \mathrm{L}$. O estudo foi realizado em uma bacia com área de $72 \mathrm{~km}^{2}$. Ziegler et al. (2014) puderam identificar concentração máxima de $15,9 \mathrm{~g} / \mathrm{L}$, com 19,9 m³/s de pico de vazão máxima, durante um evento na Bacia Mae Sa $\left(74 \mathrm{~km}^{2}\right)$, na Tailândia. Este estudo, porém, foi realizado com amostragens manuais na superfície do rio. Fatores que contribuem para o aumento na quantidade de sedimentos transportados são as monções e ciclones.

O rio com maiores concentrações de sedimento no mundo é o Rio Amarelo, na China, com média anual de 37,6 g/L (Shen e Julien, 1993). Segundo Xu (2002), na região central desse rio ou em alguns de seus tributários, é comum que a concentração de sedimentos atinja $300 \mathrm{~g} / \mathrm{L}$ em tempestades relativamente fortes, enquanto hiperconcentrações máximas de até $1 \mathrm{~kg} / \mathrm{L}$ já foram encontradas também nesses locais. A Bacia do Rio Amarelo está localizada em região montanhosa e com um tipo de solo muito suscetível à erosão, o loess.

Os resultados obtidos neste estudo mostram que o maior valor de concentração registrado pelo RF foi de $11,34 \mathrm{~g} / \mathrm{L}$, e a vazão máxima, de $64,44 \mathrm{~m}^{3} / \mathrm{s}$. Na sub-bacia do $R F$, um fator preponderante que influencia a concentração de sedimentos é a intensa urbanização existente.

No entanto, trata-se de estudos em bacias com características ambientais diferentes, o que justifica a diferença nas concentrações encontradas entre estes estudos, bem como entre os resultados obtidos no RF (Tabela 2).

No presente estudo, no CRF, as três formas de histerese mais comuns (Minella et al., 2011) foram vistas em eventos (Figura 9). Do total de 29 eventos, 15 foram observados nas formas mais comuns (sentido horário, sentido anti-horário e em formato de 8). Com relação a essas três formas, o tipo de histerese predominante foi no sentido anti-horário (60\% das representações), indicando que existe tendência de as fontes dos sedimentos estarem localizadas em ambientes mais distantes (como as vertentes). O laço no sentido horário ocorreu somente em dois eventos (13\% de representatividade). O laço em formato de 8 foi o segundo mais frequente ( $27 \%$ das representações), indicando a possibilidade de que as fontes de sedimentos nesses eventos foram tanto o próprio leito do córrego quanto fontes mais distantes na sub-bacia do RF.

A maior quantidade de sedimento em um evento com amostragem que varia com a cota resultou em um total de $1.258 \mathrm{t}$, e a menor quantidade foi de $43 \mathrm{t}$. Na amostragem fixa, o maior valor ficou em $10.142 \mathrm{t}$, enquanto o menor valor foi de $47 \mathrm{t}$. 
Tabela 2. Resumo das concentrações máximas de sedimentos em suspensão encontradas em outros trabalhos que utilizaram amostradores automáticos do tipo ISCO.

\begin{tabular}{|c|c|c|c|c|c|}
\hline Área $\left(\mathrm{km}^{2}\right)$ & $\begin{array}{l}\text { Q máximo } \\
\left(\mathrm{m}^{3} / \mathrm{s}\right)\end{array}$ & $\begin{array}{l}\text { Concentração } \\
\text { máxima (mg/L) }\end{array}$ & $\begin{array}{l}\text { Evento anômalo } \\
\text { (mg/L) }\end{array}$ & Autores & $\begin{array}{l}\text { Características } \\
\text { que influenciam } \\
\text { a quantidade de } \\
\text { sedimentos }\end{array}$ \\
\hline 311 & 97,71 & 4.797 & - & Gao e Josefson (2012) & Bacia rural \\
\hline 72 & 23,5 & 7.300 & 37.600 & De Girolamo et al. (2015) & Região montanhosa \\
\hline 74 & 19,9 & 15.900 & - & Ziegler et al. (2014) & $\begin{array}{l}\text { Bacia atingida por } \\
\text { monções e ciclones }\end{array}$ \\
\hline 752.443 & - & 300.000 & 1.000 .000 & $\begin{array}{l}\text { Shen e Julien (1992); Xu } \\
\text { (2002) }\end{array}$ & $\begin{array}{c}\text { Tipo de solo, relevo } \\
\text { montanhoso }\end{array}$ \\
\hline 171,26 & 64,44 & 11.345 & 10.691 & Próprio autor & Urbanização intensa \\
\hline
\end{tabular}

A

\section{Evento 08/12/2016}

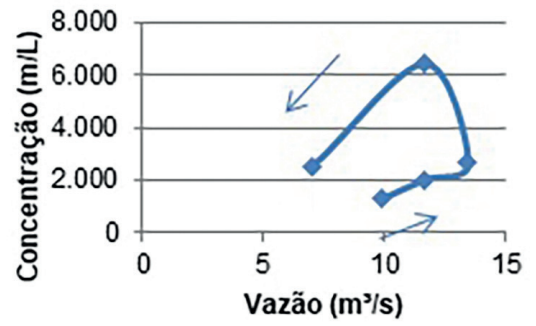

B

\section{Evento13/12/2016}

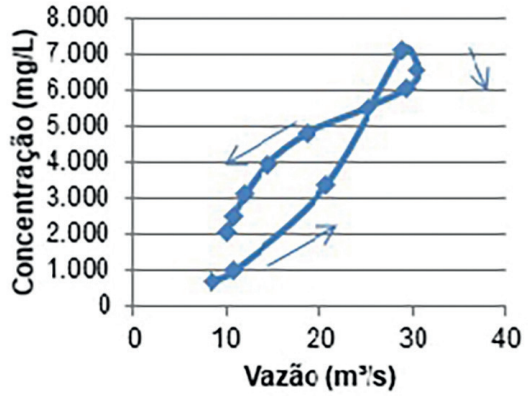

C

\section{Evento 16/01/2017}

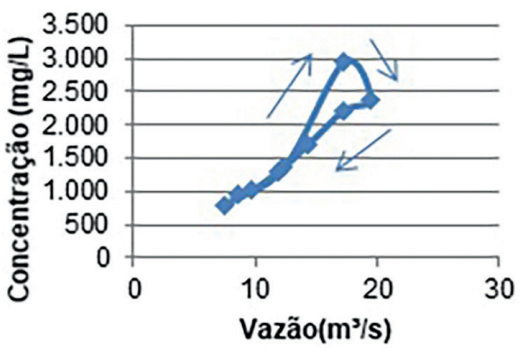

Figura 9. Três tipos de histerese encontradas durante estudo na Estação 60478200 Riacho Fundo Montante Zoo. (A) Laço anti-horário. (B) Laço com formato de oito. (C) Laço horário.

Os dados de descarga sólida total por evento (Figura 10) são visivelmente mais dispersos com o método de amostragem fixa, ao contrário dos dados que foram obtidos a partir do método de amostragem com a cota variando.

No caso da variação com a cota, o evento foi do dia 13 de janeiro de 2017, com pico de vazão próximo a $23 \mathrm{~m} / \mathrm{s}$. Para essa metodologia de amostragem, foi o segundo maior evento (em termos de pico de vazão) em que foi possível fazer amostragem de sedimento. O maior evento com amostragem foi o do dia 17 de janeiro de 2017 , chegando a $29 \mathrm{~m}^{3} / \mathrm{s}$ de pico de vazão, mas foi um evento com menor duração. Assim, no total, o evento do dia 13 de janeiro de 2017 durou 450 minutos, enquanto o outro durou 180 minutos.

Comparando a quantidade total de sedimentos por evento (Documento Suplementar I), utilizando a curva-chave da CAESB e a curva-chave gerada neste trabalho. Os dados indicam que há superestimação de sedimentos quando a curva-chave da CAESB é utilizada como base. Esses resultados refletem a dificuldade que a empresa tem enfrentado

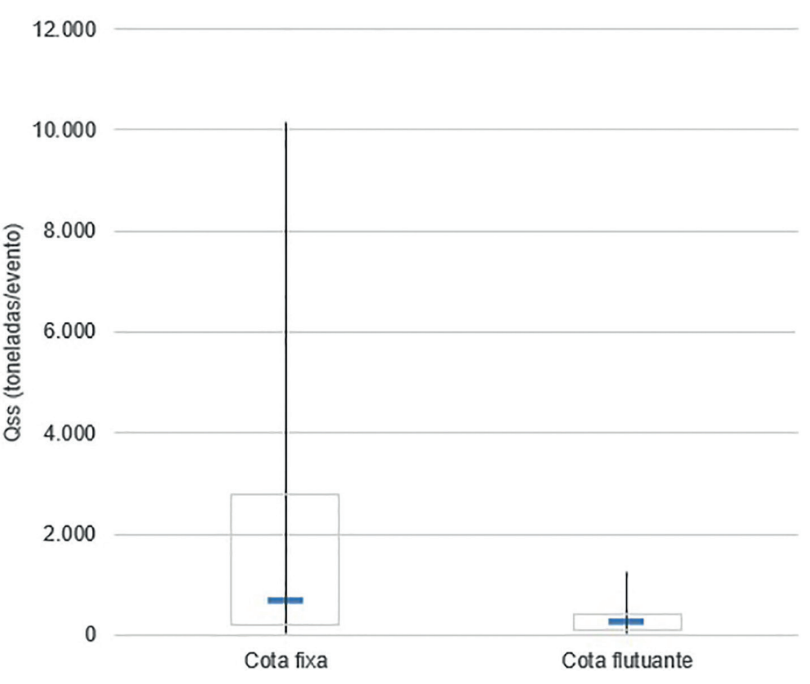

Figura 10. Boxplot dos valores de descarga de sedimento total de cada evento, em toneladas, considerando as cotas flutuante e fixa. 
no monitoramento, situação que não é exclusividade brasileira. Segundo Ndomba et al. (2008), é comum que países em desenvolvimento possuam dificuldades de manter monitoramento de sedimentos fluviais; inclusive, muitas vezes, o monitoramento deixa de ser efetuado.

Os estudos publicados envolvendo o cálculo de sedimentos em suspensão por evento, com amostradores automáticos, não são muito comuns. López-Tarazón et al. (2009) trabalharam com amostrador automático ISCO e amostras manuais com integração em uma bacia montanhosa na Espanha $\left(445 \mathrm{~km}^{2}\right)$ e também não foi possível estabelecer uma curva-chave de sedimentos, devido à dispersão dos dados de cota concentração. Em estudo realizado por López-Tarazón et al. (2009), ocorreu uma variação de picos de cheia entre 29 e $88 \mathrm{~m}^{3} / \mathrm{s}$ e total produzido de sedimentos entre 426 e 86.430 t. Rovira e Batalla (2006), em uma bacia na Espanha $\left(894 \mathrm{~km}^{2}\right)$, com dados de sedimentos em suspensão com vazões de 10,1 até $196,8 \mathrm{~m}^{3} / \mathrm{s}$, relataram quantidade por evento com variação de $64 \mathrm{t}$ (pico de $10,9 \mathrm{~m}^{3} / \mathrm{s}$ ), chegando a $61.245 \mathrm{t}\left(196,8 \mathrm{~m}^{3} / \mathrm{s}\right)$.

São rios que alcançam vazões mais altas que o CRF e, de modo geral, comparando eventos com picos máximos de vazão próximos, tanto em López-Tarazón et al. (2009) quanto em Rovira e Batalla (2006) ocorre maior transporte de sedimentos do que no CRF. O Rio Amarelo, exportador de sedimentos com maiores concentrações do mundo, chegou a produzir, em dois eventos excepcionalmente extremos, 20,8 $\times 10^{8}$ t (Ren e Shi, 1986).

Com relação aos dados de outros trabalhos citados aqui, quanto à concentração de sedimentos e à quantidade produzida por evento, devem ser consideradas as diferenças das características ambientais das bacias citadas, como, por exemplo, relevo, clima, tipo e cobertura do solo. Apesar de parte considerável dos trabalhos ter descrito concentrações e quantidades maiores que os resultados mostrados neste trabalho, o histórico de assoreamento do braço do RF mostra uma situação preocupante, que permanece em andamento. Por isso, e devido à ausência de informações de quantidade de sedimentos e vazão em cotas altas no CRF anteriores a este trabalho, é possível reconhecer a importância que as informações geradas nesta pesquisa trouxeram para a região de Brasília. Nesse sentido, o conhecimento sobre a quantidade de sedimentos transportada pelo córrego é um indicativo básico da necessidade de concentrar ações para mitigar o assoreamento do LP.

\section{Correlação turbidez e concentração}

A comparação entre turbidez (medida in situ) e concentração (obtida no laboratório a partir da amostra coletada no campo) revela boa correlação, $\mathrm{R}^{2}=92$ (Figura 11).

No entanto, para uma comparação mais precisa, é necessário que haja aumento no esforço amostral e na coleta de dados, assim como análise da granulometria e da composição dos minerais nos sedimentos.

$\mathrm{Na}$ mesma bacia e utilizando o mesmo procedimento, Aguiar (2015) alcançou também uma relação $\mathrm{R}^{2}=0,92$. Porém, no caso de Aguiar (2015), a sonda foi instalada de modo fixo e com dados de apenas um evento, haja vista que apenas um em oito eventos obteve boa correlação entre os dados. Diferentemente de Aguiar (2015), todos os dados registrados pela sonda, dentro dos seus limites de detecção, puderam ser correlacionados.

Ziegler et al. (2014) trabalharam com a estimativa de concentração a partir de dados de turbidez, em uma bacia na Tailândia. De modo análogo ao realizado neste trabalho, o registro de dados de turbidez foi feito entre 10 e $20 \mathrm{~cm}$ da superfície da água, com o auxílio de um cano PVC apoiado em uma ponte. Esse cano servia como veículo para a passagem do turbidímetro, que descia preso a uma corda. Para amostragem de água e sedimentos, foi feita a coleta manual em recipientes. A relação entre turbidez e concentração alcançou bom resultado de regressão, a partir de um modelo exponencial, em que $\mathrm{R}^{2}=0,87$. Tais resultados mostram a viabilidade de monitoramento da quantidade de sedimentos no CRF, a partir do monitoramento da turbidez.

\section{Composição mineral}

Para a composição mineral, dois conjuntos de amostras, datas e metodologia distintas foram selecionados. Trata-se de amostras coletadas em eventos que atingiram vazões máximas equivalentes (próximas a $30 \mathrm{~m}^{3} / \mathrm{s}$ ). Um dos conjuntos refere-se à data de 11 de janeiro de 2016 (Figura 12) e suas amostras foram coletadas com amostragem fixa.

\section{Turbidez sonda versus concentração - seleção de dados}

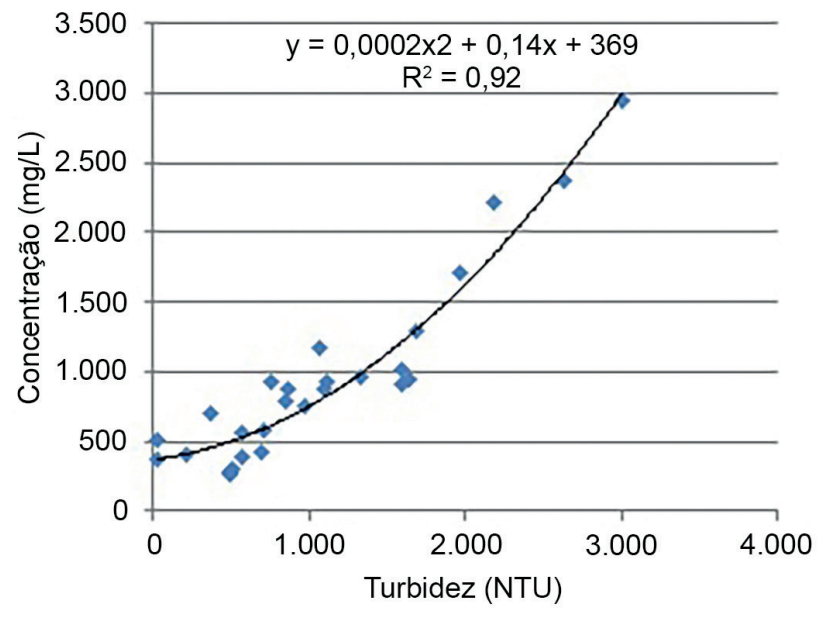

Figura 11. Gráfico de dispersão de turbidez versus concentração medido pela sonda multiparamétrica $(n=28)$. 
O outro conjunto, de 17 de janeiro de 2017 (Figura 13), foi resultado de amostragem em função da variação da cota.

Os minerais nos sedimentos em suspensão encontrados estão listados na Tabela 3 e na Tabela 4. Os principais

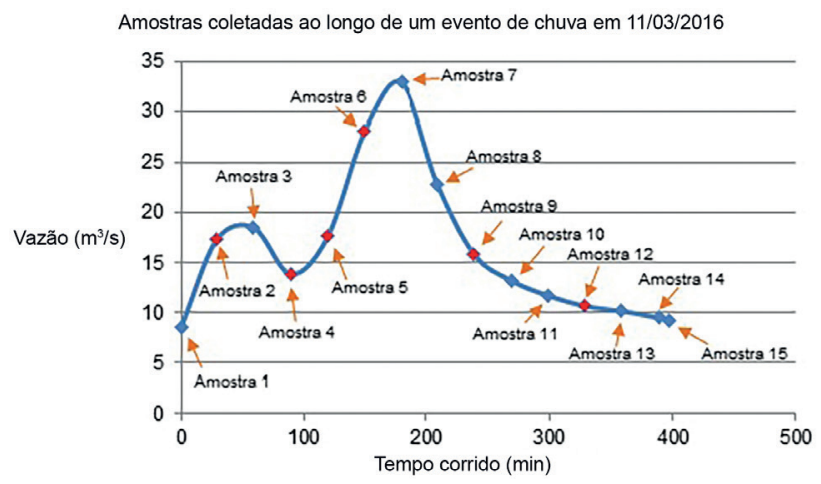

Figura 12. Gráfico mostra a representatividade das amostras escolhidas ao longo de um evento de chuva de março de 2016 no Córrego Riacho Fundo, Brasília, Distrito Federal. Foram escolhidas aleatoriamente as amostras de número 2 , 4, 5, 6, 9 e 12 para a realização do presente estudo.

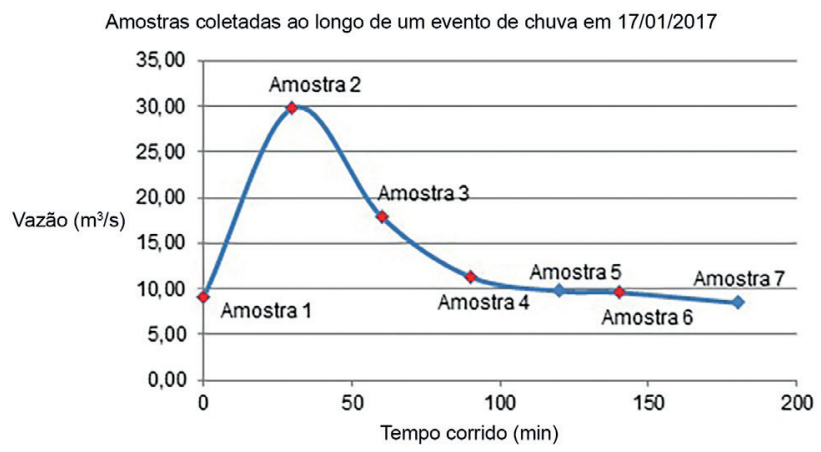

Figura 13. Gráfico mostra a representatividade das amostras escolhidas ao longo de um evento de chuva de janeiro de 2017 no Córrego Riacho Fundo, Brasília, Distrito Federal. Foram escolhidas aleatoriamente as amostras de número 1, 2, 3, 4 e 6 para a realização do presente estudo. minerais encontrados são: gibbsita $(\mathrm{d} \sim 4,8 \AA \AA)$, quartzo $(\mathrm{d} \sim 3,3 \AA$ ) e hematita $(\mathrm{d} \sim 2,69 \AA)$. Podemos destacar a presença de argilominerais tais como saponita ( $d \sim 14,3 \AA)$, vermiculita (d 14A), illita $(d \sim 10 \AA)$ e caulinita $(d \sim 7 \AA)$. Foram também encontrados muscovita $(\mathrm{d} \sim 10 \AA)$, diásporo $(\mathrm{d} \sim 4,7 \AA)$ e rutilo ( $\mathrm{d} 3,24 \AA$ ). Por fim, há indício de detecção de anatásio próximo às reflexões secundárias da caulinita e de goethita próximo às reflexões de quartzo $(\mathrm{d} \sim 4,2)$.

$\mathrm{O}$ conjunto de amostras do dia 11 de março de 2016 e uma das amostras do dia 17 de janeiro de 2017 (amostra 4) não apresentaram a ausência das reflexões de intensidade da caulinita após aquecimento (Documento Suplementar II). Esse fato evidencia a presença de um tipo de caulinita bem cristalizado, com estrutura bem definida, de modo que seria necessária uma temperatura mais elevada para o desaparecimento total dos registros de intensidade provindos da reflexão dos raios $\mathrm{X}$ nos planos cristalinos.

É possível notar, quanto ao evento do ano de 2016 (Documento Suplementar II), que as reflexões da illita são maiores que as da gibbsita $(e m n=1$, sendo $n=$ ordem de difração), mas vão diminuindo progressivamente ao longo do evento, enquanto os de gibbsita aumentam. Esse processo continua até que a reflexão desse mineral ultrapasse a da illita. Esse fato, embasado ainda nos difratogramas de solo e rocha (ardósia do Grupo Paranoá) coletados dentro da sub-bacia do RF (Figura 14), é um indicativo de que a contribuição a partir das rochas é maior no início e menor no final do evento, tendo mais influência do solo a posteriore.

Com exceção do mineral saponita, os demais minerais identificados aqui já foram encontrados na região estudada, seja na própria sub-bacia do RF ou nos sedimentos de fundo do braço do LP, que é abastecido pelo CRF (Moreira e Boaventura, 2003; Reatto et al., 2004; Maia et al., 2005; Gioia et al., 2006; Echeverria, 2007; Dias, 2017). No entanto, esses trabalhos mostram que existem proporções diversas (constituinte maior, menor e traço) entre os tipos de minerais encontrados, sendo a illita, a caulinita, o quartzo e a gibbsita os mais abundantes, como esperado, devido à geologia e às condições intensas de

Tabela 3. Minerais identificados com o método de amostragem fixa.

\begin{tabular}{|c|c|c|c|c|c|c|}
\hline Evento 11/03/2016 & Amostra 2 & Amostra 4 & Amostra 5 & Amostra 6 & Amostra 9 & Amostra 12 \\
\hline Hematita & $x$ & $x$ & $x$ & $x$ & $X$ & $x$ \\
\hline Illita & $x$ & $x$ & $x$ & $x$ & $x$ & - \\
\hline Caulinita & $x$ & $x$ & $x$ & $x$ & $x$ & $x$ \\
\hline Diásporo & - & - & - & - & - & $x$ \\
\hline Quartzo & $x$ & $x$ & $X$ & $x$ & $x$ & $x$ \\
\hline Muscovita & - & - & - & - & - & $x$ \\
\hline Rutilo & $x$ & $x$ & $x$ & $x$ & $x$ & $x$ \\
\hline Gibbsita & $x$ & $x$ & $x$ & $x$ & $x$ & $x$ \\
\hline Vermiculita & - & - & - & X & $x$ & - \\
\hline Saponita & - & - & - & - & - & $X$ \\
\hline
\end{tabular}


intemperismo na região. É importante dizer que, dentre as pesquisas supracitadas, nem todas obtiveram exatamente os mesmos resultados. Sendo assim, o mineral vermiculita, por exemplo, somente foi encontrado por Maia et al. (2005). A presença do diásporo não chegou a ser confirmada em Echeverria (2007), apesar de seu indício no Córrego Guará (componente da sub-bacia do RF), mas apareceu como resultado em Gioia et al. (2006).

De modo geral, os resultados dos difratogramas em cada amostra foram bastante semelhantes quanto aos minerais

Tabela 4. Minerais identificados com o método de amostragem com a cota variável e filtro flutuando na superfície da água.

\begin{tabular}{lccccc}
\hline Evento 17/01/2017 & Amostra 1 & Amostra 2 & Amostra 3 & Amostra 4 & Amostra 6 \\
\hline Hematita & $X$ & $X$ & $X$ & $X$ & $X$ \\
Illita & - & - & - & - & - \\
Caulinita & $X$ & $X$ & $X$ & $X$ & $X$ \\
Diásporo & $X$ & $X$ & $X$ & $X$ & $X$ \\
Quartzo & $X$ & $X$ & $X$ & $X$ & $X$ \\
Muscovita & $X$ & $X$ & $X$ & $X$ & $X$ \\
Rutilo & $X$ & $X$ & $X$ & $X$ & $X$ \\
Gibbsita & $X$ & - & - & - & - \\
Vermiculita & - & - & $X$ & - & $X$ \\
Saponita & - & $X$ & & $X$ & - \\
Anatásio & $X$ & & $X$ & & \\
\hline
\end{tabular}

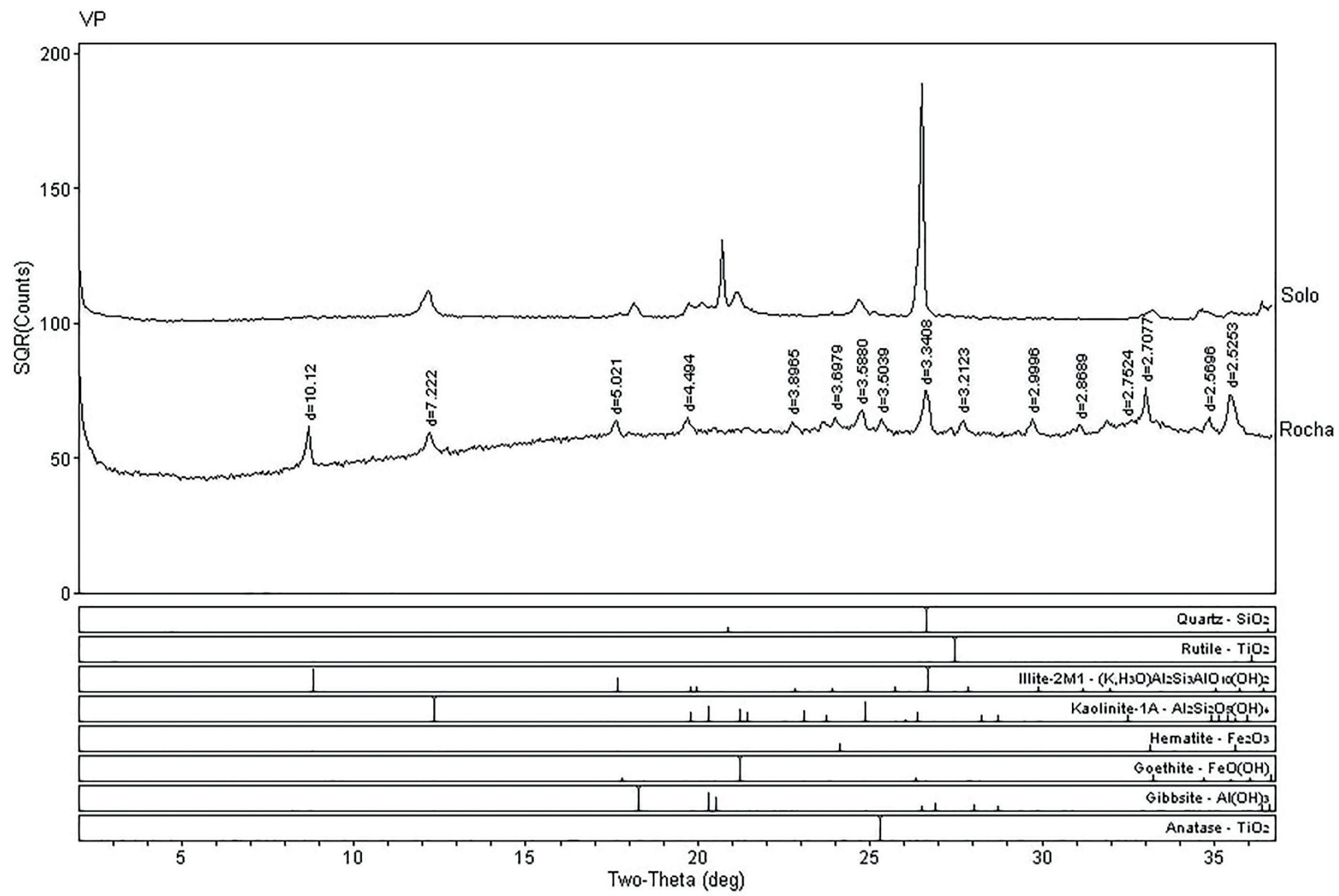

Campus Univ Darcy Ribeiro

[RAIO-X||G] Monday, March 26, 2018 03:03p (MDIJJADE9)

Figura 14. Difratometria de raio $X$ de uma amostra de solo e rocha da sub-bacia do Córrego Riacho Fundo. 
identificados em todas as amostras. Porém, a saponita só foi vista em uma amostra de cada dia e o diásporo, presente em todas as amostras do evento de 2017, indicou presença somente em uma amostra do evento do ano de 2016. Outro fato a ser considerado foi a presença de vermiculita em somente duas amostras de 11 de março de 2016. Esses fatos mostram a capacidade do amostrador automático para monitorar com mais detalhes não apenas a carga, mas a variabilidade nos sedimentos carreados pelo RF.

\section{CONSIDERAÇÕES FINAIS}

A partir deste novo estudo sedimentométrico do RF e mais especificamente da implantação de uma nova abordagem:

- Foi possível construir uma curva-chave adequada para medição de vazão em cheias. Com isso, concluiu-se que o uso da curva-chave da CAESB superestima a quantidade de sedimentos nos eventos de cheia;

- Este trabalho também contribuiu para a geração de dados sedimentométricos para o Reservatório do Lago Paranoá, com frequência de amostragem e representatividade de cotas ainda não observadas até o presente momento;

- Foram identificados diversos minerais nos sedimentos em suspensão, com diversidade não encontrada em um único trabalho, de todos os que já foram feitos no CRF e no braço do RF no lago;

- O uso de amostradores manuais (como os que têm sido utilizados pelas empresas responsáveis por monitoramento, a partir dos métodos consagrados) é inviável no local de estudo. Esse fato reforça a importância do uso do amostrador automático no CRF;

- É provável que o uso de métodos de interpolação estatística diminua a dispersão dos dados de vazão e concentração;

- Foi possível obter boa correlação entre turbidez e concentração. Porém, ainda é necessária a aquisição de informações da granulometria dos sedimentos para aplicar o modelo de cálculo;

- Levando-se em consideração a questão de planejamento, é melhor trabalhar com uma superestimativa a uma subestimativa de total exportado de sedimento para um reservatório. Porém, apesar de a curva-chave da CAESB superestimar a quantidade de água, não há monitoramento efetivo de sedimento nas cotas mais altas. Considerando que a sub-bacia do RF tem parte considerável de sua área total intensamente urbanizada, aumentando o escoamento superficial e diminuindo a infiltração de água (com possíveis consequências para o fluxo de base), pode ser que o uso da curva-chave da CAESB prejudique o cálculo do balanço hídrico do LP, algo que poderia ser examinado detalhadamente em outros trabalhos;

- Para complementar as informações já adquiridas, recomenda-se que em trabalhos futuros seja feita a caracterização granulométrica para posteriores cálculos do volume total que os sedimentos estão subtraindo do volume de água a cada ano no reservatório do LP.

\section{AGRADECIMENTOS}

Os autores agradecem ao Conselho Nacional de Desenvolvimento Científico e Tecnológico (CPNq), pela bolsa vinculada ao Projeto Aquasense; ao Laboratório de Sensoriamento Remoto e Análise Espacial do IG da UnB, pela disponibilização da infraestrutura necessária; e à ESRI/ IMAGEM, pela disponibilização do pacote de ferramentas que compõem a família ArcGis 10, por intermédio do Contrato $\mathrm{n}^{\circ} 2011$ MLK 8733. Também agradecem ao professor José Eloi Guimarães Campos, do IG da UnB, acerca de discussões sobre teoria e resultados de mineralogia deste trabalho.

\section{REFERÊNCIAS}

Agência Nacional de Águas - ANA. Superintendência de Gestão da Rede Hidrometeorológica. (2011). Nota técnica $n^{\circ}$ 245/2011/SGH-ANA. Brasília: ANA, SGH, Ed. ANA.

Agência Nacional de Águas - ANA. Superintendência de Gestão da Rede Hidrometeorológica. (2012). Orientações para Operação de Estações Hidrométricas. Brasília: ANA, SGH, Ed. ANA.

Aguiar, M. R. F. (2015). Análise da Descarga Sólida em Suspensão na Bacia do Córrego Riacho Fundo (DF). Dissertação (Mestrado). Brasília: Programa de Geociências Aplicadas - UnB.

Campos, J. E. G., Dardenne, M. A., Freitas-Silva, F. H., Martins-Ferreira, M. A. C. (2013). Geologia do Grupo Paranoá na porção externa da Faixa Brasília. Brazilian Journal of Geology, 43(3), 461-476. https://doi.org/10.5327/ Z2317-48892013000300004

Carvalho, A. M. (2013). Estudo geoquímico da qualidade da água da bacia do Riacho Fundo-DF. Dissertação (Mestrado). Brasília: Instituto de Geociências - UnB.

Carvalho, N. O., Filizola Jr., N. P., Coutinhos dos Santos, P. M., Lima, J. E. F.W (2000). Guia de práticas sedimentométricas. Brasília: ANEEL.

Carvalho, N. O., Massera Da Hora, M. A. G. (2013). Hidrossedimentometria. In: C. Poleto (Ed.), Sedimentologia Fluvial: Estudos e Técnicas. Porto Alegre: Editora da Associação Brasileira de Recursos Hídricos - ABRH. 
Companhia de Planejamento do Distrito Federal CODEPLAN. (1984). Atlas do Distrito Federal. Brasília: GDF, $78 \mathrm{p}$.

Companhia de Saneamento Ambiental do Distrito Federal - CAESB. (2013). Dados brutos ano 2013 levantamento perfil transversal da seção de monitoramento da estação 60478200 Riacho Fundo Montante Zoológico. Brasília: CAESB, PRHR.

Companhia de Saneamento Ambiental do Distrito Federal - CAESB. (2014). Dados brutos ano 2014 levantamento perfil transversal da seção de monitoramento da estação 60478200 Riacho Fundo Montante Zoológico. Brasília: CAESB, PRHR.

Companhia de Saneamento Ambiental do Distrito Federal - CAESB. (2015). Arquivo shape da Sub-bacia do Córrego Riacho Fundo. Brasília: CAESB, PRHR.

Companhia de Saneamento Ambiental do Distrito Federal - CAESB. (2016). Dados brutos ano 2016 levantamento perfil transversal da seção de monitoramento da estação 60478200 Riacho Fundo Montante Zoológico. Brasília: CAESB, PRHR.

Companhia de Saneamento Ambiental do Distrito Federal - CAESB. (2017). Artigo do Presidente da Caesb Maurício Luduvice publicado no Correio Braziliense em 16/01/2017. Boletim eletrônico. Disponível em: <https://www.caesb. df.gov.br/component/content/article/27-portal/567-seca2016-2017-outras-informacoes.html>. Acesso em: jul. 2017.

Costa, N. Y. M. (2014). Estudo geoquímico e de contaminantes emergentes na bacia do lago Paranoá. Dissertação (Mestrado). Brasília: Universidade de Brasília.

De Girolamo, A. M., Pappagallo, G., Porto, A. L. (2015). Temporal variability of suspended sediment transport and rating curves in a Mediterranean river basin: The Celone (SE Italy). Catena, v. 128, p. 135-143. http://dx.doi.org/10.1016/j.catena.2014.09.020

Dias, D. F. (2017). Processos Geoquímicos na Interface Sedimento-Água no Braço Riacho Fundo do Lago Paranoá - DF. 88f. Dissertação (Mestrado). Brasília: Instituto de Geociências - UnB.

Echeverria, R. M. (2007). Avaliação de impactos ambientais nos tributários do lago Paranoá, Brasília-DF. Dissertação (Mestrado). Brasília: Instituto de Geociências - UnB.

Franz, C., Abbt-Braun, G., Lorz, C., Roig, H. L., Makeschin, F. (2014). Assessment and evaluation of metal contents in sediment and water samples within an urban watershed: an analysis of anthropogenic impacts on sediment and water quality in Central Brazil Environmental Earth Science, 72, 4873-4890. https://doi.org/10.1007/s12665-014-3454-8

Gao, P., Josefson, M. (2012). Temporal variations of suspended sediment transport in Oneida Creek watershed, central New York. Journal of Hydrology, 426, 17-27. https://doi. org/10.1016/j.jhydrol.2012.01.012

Gioia, S. M., Pimentel, M. M., Tessler, M., Dantas, E. L., Campos, J. E., Guimarães, E. M., Maruoka, M. T., Nascimento, E. L. (2006). Sources of anthropogenic lead in sediments from an artificial lake in Brasília-central Brazil. Science of the Total Environment, 356, 125-142. https://doi. org/10.1016/j.scitotenv.2005.02.041

Hussain, Y., Hernan, C. M., Roig, H. L. (2015). An estimation of impacts of urban growth on runoff and non-point source pollution loads by an expert coefficient approach in GIS: a case study of Federal District, Brazil. XIV Simpósio de Geologia do Centro Oeste, p. 122-129. Brasília: SBG Núcleo Brasília.

Jaccon, G. (1989). Curva-chave: análise e traçado. Brasília: DNAEE.

López-Tarazón, J. A., Batalla, R. J., Vericat, D., Francke, T. (2009). Suspended sediment transport in a highly erodible catchment: the River Isábena (Southern Pyrenees). Geomorphology, 109(3), 210-221. https://doi.org/10.1016/j. geomorph.2009.03.003

Maia, P. D., Boaventura, G. R., Pires, A. C. B. (2006) Distribuição Espacial de Elementos-Traço em Sedimentos do Lago Paranoá-DF, Brasil. Geochimica Brasiliensis, 20(2), 158-174. https://doi.org/10.21715/gb.v20i2.242

Maia, P. D., Guimarães, E. M., Moreira, R. C. A., Boaventura, G. R. (2005) Estudo mineralógico dos sedimentos de fundo do Lago Paranoá, Distrito Federal. Brazilian Journal of Geology, 35(4), 535-541.

Menezes, P. H. B. J. (2010). Avaliação do efeito das ações antrópicas no processo de escoamento superficial e assoreamento na bacia do Lago Paranoá. 123f. Dissertação (Mestrado). Brasília: Instituto de Geociências - UnB.

Menezes, P. H. B. J., Roig, H. L., Almedia, T., Neto, G. B. S., Isaias, F. B. (2010). Análise da evolução do padrão de uso e ocupação na bacia de contribuição do Lago Paranoá DF. Estudos Geográficos, 8(1), 88-106. 
Miguel, R., Roig, H. L., Oliveira, E. S. (2017). Análise do processo de assoreamento no braço do Riacho Fundo, do Lago Paranoá - DF, utilizando técnicas de geoprocessamento e sedimentometria. XV Simpósio de Geologia do Centro Oeste, p. 180-185. Goiânia: SBG - Núcleo Centro-Oeste.

Minella, J. P. G, Merten, G. H, Magnano, P. F, Reichert, J. M., Barros, C. A. P., Dalbianco, L. (2011). Efeito histerese na produção de sedimentos em bacia sob intenso processo erosivo. Engenharia de Sedimentos: na busca de soluções para problemas de erosão e assoreamento. In: J. E. F. W. Lima, W. T. A. Lopes (Eds.). Engenharia de sedimentos: na busca de soluções para problemas de erosão e assoreamento. Brasília: Ed. ABRH. cap. 2.

Moreira, R. C. A., Boaventura, G. R. (2003). Referência geoquímica regional para a interpretação das concentrações de elementos químicos nos sedimentos da bacia do Lago Paranoá-DF. Química Nova, 26(6), 812-820. http://dx.doi. org/10.1590/S0100-40422003000600006

Ndomba, P. M., Mtalo, F. W., Killingtveit, Å. (2008). Developing an excellent sediment rating curve from one hydrological year sampling programme data: approach. Journal of Urban and Environmental Engineering, 2(1), 21-27. http://dx.doi.org/10.4090/juee.2008.v2n1.021027

Reatto, A., Martins, E. D. S., Guimarães, E. M., Spera, S. T., Correia, J. R., Simm, K. M. C. B. (1999). Variabilidade mineralógica de latossolos na Bacia do Rio Jardim, DF. Embrapa Cerrados, Boletim de Pesquisa, 2. 24 p.

Reatto, A., Martins, E. S., Farias, M. F. R., Silva, A. V., Carvalho Junior, O. A. (2004). Mapa pedológico digital: SIG atualizado do Distrito Federal escala 1:100.000 e uma síntese de texto explicativo. Planaltina: Embrapa-CPAC. 31p.

Ren, M. E., Shi, Y. L. (1986). Sediment discharge of the Yellow River (China) and its effect on the sedimentation of the Bohai and the Yellow Sea. Continental Shelf Research, 6(6), 785-810. https://doi.org/10.1016/02784343(86)90037-3

Roig, H. L., Ferreira, A. M. R., Menezes, P. H. B. J., Marotta, G. S. (2013). Uso de câmeras de baixo custo acopladas a veículos aéreos leves no estudo do aporte de sedimentos no Lago Paranoá. XVI Simpósio Brasileiro de Sensoriamento Remoto, Anais. Foz do Iguaçu: INPE.

Rovira, A., Batalla, R. J. (2006). Temporal distribution of suspended sediment transport in a Mediterranean basin: The Lower Tordera (NE SPAIN). Geomorphology, 79(1), 58-71. http://dx.doi.org/10.1016/j.geomorph.2005.09.016

Shen, H. W., Julien, P. Y. (1992). Erosion and Sediment Transport. In: D. R. Maidment (Ed.), Handbook of Hydrology. New York: McGraw-Hill. Cap. 12.

Te Chow, V. (1988). Applied hydrology. Singapore: Tata McGraw-Hill Education.

Veiga, L. A. K., Zanetti, M. A. Z., Faggion, P. L. (2012). Fundamentos de Topografia. Engenharia Cartográfica e de Agrimensura. Curitiba: Universidade Federal do Paraná.

Xu, J. (2002). Implication of relationships among suspended sediment size, water discharge and suspended sediment concentration: the Yellow River basin, China. Catena, 49(4), 289-307. https://doi.org/10.1016/ S0341-8162(02)00064-4

Ziegler, A. D., Benner, S. G., Tantasirin, C., Wood, S. H., Sutherland, R. A., Sidle, R. C., Jachowski, N., Nullet, M. A., Xi, L. X., Snidvongs, A., Giambelluca, T. W., Fox, J. M. (2014). Turbidity-based sediment monitoring in northern Thailand: Hysteresis, variability, and uncertainty. Journal of Hydrology, 519, 2020-2039. https://doi.org/10.1016/j. jhydrol.2014.09.010 